$\xi_{p}$

\title{
Prevalence of hypertension and pre-hypertension among secondary school students
}

\author{
Jamal Qaddumi ${ }^{1}$, Margo Holm ${ }^{2}$, Abdullah Alkhawaldeh ${ }^{3}$, Mohammed Albashtawy ${ }^{4}$, Omar AL Omari ${ }^{3}$, \\ Abdul-Monim Batiha * ${ }^{5}$, Fadwa Alhalaiqa ${ }^{5}$, Mohammad Suliman ${ }^{4}$, Khalid Aljohani ${ }^{6}$, Ayat Da'she ${ }^{7}$ \\ ${ }^{1}$ Faculty of Medicine and Health sciences, An-Najah National University, Palestine \\ ${ }^{2}$ University of Pittsburgh, Pittsburgh, Faculty of Health and Rehabilitation Sciences, USA \\ ${ }^{3}$ Faculty of Nursing, Jerash University, Jordan \\ ${ }^{4}$ Princess Salma Faculty of Nursing, AL al-Bayt University, Jordan \\ ${ }^{5}$ Faculty of Nursing, Philadelphia University, Jordan \\ ${ }^{6}$ Faculty of Nursing, Taibah University, Saudi Arabia \\ ${ }^{7}$ Al-Balqa Applied University, Jordan \\ *Corresponding author E-mail: abatiha@philadelphia.edu.jo
}

\begin{abstract}
Hypertension and pre-hypertension are major contributors to morbidity. Early detection of hypertension and pre-hypertension among adolescents may prevent their complications. A cross-sectional study was conducted to estimate the prevalence of hypertension and prehypertension among adolescents attending government high schools in Nablus city, Palestine and to identify associated factors, in a sample of 487 adolescents aged 16-18 years in the year 2016. Associations between hypertension, pre-hypertension and known contributing factors were analyzed with Chi-square tests.

The prevalence of hypertension and pre-hypertension were 59.2\%. Body Mass Index (BMI) was significantly associated with a greater prevalence of hypertension (normal weight $13.1 \%$, overweight $33.3 \%$, and obesity $54.8 \%$ ) and pre-hypertension (normal weight $40.4 \%$, overweight $47.4 \%$ and obesity $40.5 \%$ ).

The results confirmed a prevalence of hypertension and pre-hypertension among adolescents. Of known contributing factors studied, gender, age, BMI, and family history of hypertension were significantly associated with a greater prevalence of hypertension or prehypertension.
\end{abstract}

Keywords: School Students; Hypertension; Pre- Hypertension; Adolescents.

\section{Introduction}

Globally, pre-hypertension and hypertension are associated with major morbidity across all age groups. Hypertension is one of the most common chronic illnesses that is described as a "silent killer" (Park, 2007). It is responsible for at least $51 \%$ of deaths due to stroke and $45 \%$ of deaths due to heart disease (World Health Organization [WHO], 2008). Pre-hypertension, is a systolic blood pressure of $120-139 \mathrm{mmHg}$ and a diastolic blood pressure of 80 $89 \mathrm{mmHg}$ (Chobanian, et al., 2003a), can affect the vital organs in the same way as hypertension (Lucini, Mela, Malliani, \& Pagani, 2002). It has also been recognized to have relationship with increased incidence of cardiovascular disease (Ferdinand \& Pacini, 2007; Tawalbeh, Tubaishat, Batiha, AlAzzam \& ALBashtawy, 2015).

There is an emerging increase in the prevalence of hypertension and pre-hypertension among adolescents. In Portugal, among adolescents, 34\% had hypertension and $12 \%$ pre-hypertension (Silva et al., 2012). In Africa, a prevalence of 5.4\% and $17.3 \%$ hypertension and pre-hypertension, respectively, was reported in Nigerian adolescents (Ujunwa, Ikefuna, Nwokocha \& Chinawa, 2013). In India, school children aged 13 and 17 years had a prevalence of $6.75 \%$ hypertension and $8.4 \%$ pre-hypertension (Shetty, Shetty, Sasidharan \& Shenoy, 2013). However, another study found the prevalence of hypertension in Indian adolescents was $21.5 \%$ (Sundar et al., 2013).

Hypertension and pre-hypertension have been found to be associated with several predisposing factors. Body Mass Index (BMI) and a family history of hypertension were two factors (Silva et al., 2012). Sundar et al., in 2013, added gender as another major contributing factor, in addition to a low level of awareness regarding hypertension among adolescents aged 13-17 years. Socioeconomic status, fruit and soft drink consumption were also found to play a role in the prevalence of both hypertension and prehypertension (ALBashtawy et al., 2014; Amma, Vasudevan, \& Akshayakumar, 2015). Previous research also identified some of the same factors (Bahl, Singh \& Sabharwal, 2015; Rafraf, Gargari \& Safaiyan, 2010; Ujunwa et al., 2013). However, against expectations, age, smoking and alcohol intake were not associated with hypertension and pre-hypertension among adolescent by Amma et al., (2015) and Oyewole \& Oritogun (2012).

In Palestine, little data exist about the prevalence of hypertension and pre-hypertension among adolescents. Complications of hypertension and pre-hypertension may influence quality of life (Arima et al., 2012; Batiha et al. 2015). Therefore, early detection of hypertension and pre-hypertension among adolescents, as well as health promotion programs with rapid interventions, may prevent their complications (Al-ghzawi, ALBashtawy, Azzeghaiby \& 
Azzeghaiby, 2014; Chobanian, et al., 2003b; Alkhawaldeh et al., 2016; Khamaiseh, A. \& ALBashtawy, M, 2013). The current study aimed (a) to estimate the prevalence of hypertension and pre- hypertension among adolescents attending government high schools in Nablus city, Palestine and (b) to identify factors associated with hypertension and pre- hypertension.

\section{Methods}

\subsection{Study design}

A cross-sectional study design was used to explore the prevalence of hypertension and pre-hypertension among adolescents aged between 16 and 18 years old within the study period in the year 2016.

\subsection{Setting}

The study was conducted in secondary government schools in Nablus city, situated within Nablus governorate in north part of Palestine.

\subsection{Sampling and selection of participants}

In the current study, the target population consisted of all eligible adolescents who lived within the Nablus governorate. The accessible population consisted of all adolescents who studied within the selected secondary government schools in Nablus city within Nablus governorate. This study was conducted on a representative sample of 487 adolescents aged 16 to 18 years old, in 11 of the secondary government schools in Nablus city. Inclusion criteria were (a) 16-18 years of age; and (b) able to tolerate a 25-minute interview. The following students were excluded: (a) students under 16 years and over 18 years; (b) students in private schools; and (c) pregnant students.

\subsection{Ethical considerations}

Permission to conduct the study was obtained from Research Center at An-Najah National University Institutional Review Board (IRB), the Ministry of Education and Directorate of Higher Education in Nablus. Parental consent was obtained after a full explanation about the study purpose, the right to refuse to participate, and the protection of anonymity and confidentiality of the participation was guaranteed.

\subsection{Data Collection}

The data for the current study were collected in two steps on the same day:

- Step one included recording the socio-demographic data of the students and taking a brief medical history.

- Step two included measurement of blood pressure and anthropometric data collection.

Blood pressure was measured on the non-dominant arm using a mercury sphygmomanometer at heart level and using the appropriate cuff size. The students were allowed to rest up to 5 minutes in a sitting position before measuring their blood pressure. Operational definitions of hypertension, pre-hypertension and normotensive for this study, based on the 4th report on the diagnosis, evaluation, and treatment of high blood pressure in children and adolescents (2004), were:

The participant whose average systolic and/or diastolic blood pressure is $\geq 95$ th percentile for gender, age, and height on 3 or more separate occasions is considered as having hypertension. The participant whose average blood pressure levels are $\geq 90$ th percentile but $<95$ th percentile is considered as prehypertension. The participant whose average blood pressure levels are $<90$ th percentile is classified as normotensive.
Weight was measured using electronic scales after removal of shoes and heavy clothing. Height was recorded using meters. The BMI was calculated from the measured weight (in kilograms) and height (in centimeters) and was classified as normal weight, overweight, or obese, consistent with WHO criteria (WHO, 1997).

\subsection{Statistical analyses}

Data were analyzed using the Statistical Package for the Social Sciences (SPSS) version 17.0 (Statistics for Windows, Version 17.0. Chicago: SPSS Inc.). Contributing factors were summarized as frequencies and percentages and dichotomized or trichotomized. Chi-square tests were used to test the associations between blood pressure categories (hypertension, pre-hypertension, normotensive) and factors previously identified as contributing to hypertension and pre-hypertension. The significance level was set at $\mathrm{P}<$ $0.05)$.

\section{Results}

\subsection{Characteristics of participants}

A total of 487 students were studied, of which 277 (56.9\%) were boys and $210(43.1 \%)$ were girls. Half of the students were aged 16 years old. In terms of BMI, the majority of the students had normal body weight. Most of the students were also nonsmokers. More than half of students reported that they participated in physical activity and two-thirds of the students did not have a family history of hypertension. Finally, about two-thirds of the students had knowledge of hypertension (see Table 1).

Table 1: Distribution of the Study Sample According to Study Variables

\begin{tabular}{llll}
\hline Variable & & Frequency & $\begin{array}{l}\text { Percentage } \\
(\%)\end{array}$ \\
\hline Gender & Boys & 277 & $56.9 \%$ \\
& Girls & 210 & $43.1 \%$ \\
Age & 16 years & 274 & $56.3 \%$ \\
& 17 years & 189 & $38.8 \%$ \\
& 18 years & 24 & $4.9 \%$ \\
BMI & Normal & 359 & $73.7 \%$ \\
& Over weight & 57 & $11.7 \%$ \\
Smoking & Obese & 42 & $8.6 \%$ \\
& Yes & 57 & $11.7 \%$ \\
& No & 430 & $88.3 \%$ \\
Physical exercise & Yes & 268 & $55.0 \%$ \\
& No & 219 & $45.0 \%$ \\
Family history of hyper- & Yes & 166 & $34.1 \%$ \\
tension & No & 321 & $65.9 \%$ \\
Knowledge about hyper- & Yes & 297 & $61.0 \%$ \\
tension & No & 190 & $39.0 \%$ \\
\hline
\end{tabular}

\subsection{The prevalence of hypertension and pre- hypertension}

About $18.7 \%$ of the students met the hypertension criteria and $40.5 \%$ met the criteria for pre-hypertension. The remaining $40.9 \%$ of the students had a normotensive blood pressure reading.

\subsection{Level of awareness about hypertension}

In the current study, almost two-thirds of the students had knowledge about hypertension. However, $39.0 \%$ of the students had no knowledge about hypertension.

Hypertension versus pre-hypertension versus normotensive blood pressure

Gender. The prevalence of normotensive was significantly greater among boy students compared with the prevalence of hypertension 
and pre-hypertension. In contrast, the prevalence of prehypertension was greater among girl students compared with the prevalence of hypertension and normotensive (see Table 2).

Age. Among 16 year olds, the prevalence of pre-hypertension was significantly greater than the prevalence of hypertension and normotensive. Among 17 year olds, the prevalence of normotensive was significantly greater compared with the prevalence of hypertension and pre-hypertension. There were no differences among levels for the 18 year olds (see Table 2).

BMI. The prevalence of normotensive was significantly greater among students categorized as normal weight compared with those categorized with hypertension and pre-hypertension. For those categorized as overweight, significantly more were prehypertensive compared to hypertensive or normotensive. Among students categorized as obese significantly more had hypertension versus pre-hypertension or normotensive (see Table 2).

Smoking. For students categorized as smokers, the prevalence of pre-hypertension was significantly greater than hypertension or normotensive. The prevalence of normotensive was significantly greater among students categorized as nonsmokers compared with the prevalence of hypertension and pre-hypertension (see Table 2). Physical exercise. The prevalence of pre-hypertension was greater among students categorized as having practiced physical exercise compared with the prevalence of hypertension and normotensive. In contrast, the prevalence of normotensive was greater among students categorized as not having practiced physical exercise compared with the prevalence of hypertension and prehypertension (see Table 2).

Family history of hypertension. The prevalence of hypertension was significantly greater among students categorized as having a family history of hypertension compared with the prevalence of pre-hypertension and normotensive. In contrast, the prevalence of normotensive was significantly greater among students categorized as having no family history of hypertension compared with the prevalence of hypertension and pre-hypertension (see Table 2). Demographic factors within levels of hypertension
Gender. The prevalence of hypertension among boy students was significantly greater than among girl students, whereas the differences between genders was not significantly different for prehypertension and normotensive (see Table 3 ).

Age. The prevalence of hypertension was not significantly different among 16, 17 and 18 year olds. However, among those categorized as pre-hypertensive and normotensive, there were significant differences between each age group, with 18 year olds most prevalent in each blood pressure category (see Table 3 ).

BMI. The prevalence of hypertension was significantly greater among students categorized as obese compared with overweight and normal weight students. Also, the prevalence of prehypertension was significantly greater among students categorized as overweight compared with obese and normal weight students. As expected, the prevalence of students categorized as having a normal weight were significantly greater than those categorized as overweight and obese (see Table 3).

Smoking. The prevalence of pre-hypertension among students who smoked was significantly greater than for those who did not smoke. For those students who did not smoke, their prevalence was significantly greater for hypertension and normotensive categories (see Table 3).

Physical exercise. For students who reported that they did physical exercise, the prevalence of students categorized as hypertensive and normotensive were not significantly different from those who did not exercise. However, the prevalence of pre-hypertension among students who practiced physical exercise was significantly greater than those who did not exercise (see Table 3).

Family history of hypertension. The prevalence of hypertension and pre-hypertension among students who had a family history of hypertension was significantly greater than for those with no family history. Conversely, the prevalence of normotensive among students who did not have a family history of hypertension was significantly greater than those who had a family history (see Table 3).

Table 2: Distribution of Study Participants by Blood Pressure Levels

\begin{tabular}{|c|c|c|c|c|c|}
\hline Variables & & $\begin{array}{l}\text { Hypertension } \\
(\%)\end{array}$ & $\begin{array}{l}\text { Pre hypertension } \\
(\%)\end{array}$ & $\begin{array}{l}\text { Normotensive } \\
(\%)\end{array}$ & Significance \\
\hline \multirow[t]{2}{*}{ Gender } & Boys & $23.8 \%^{\mathrm{a}}$ & $36.8 \%^{\mathrm{a}}$ & $39.4 \%^{\mathrm{b}}$ & $\mathrm{P}=0.003$ \\
\hline & Girls & $11.9 \%^{\mathrm{a}}$ & $45.2 \%{ }^{\mathrm{b}}$ & $42.9 \%^{\mathrm{a}}$ & $\mathrm{P}<0.001$ \\
\hline \multirow[t]{3}{*}{ Age } & 16 years & $18.6 \% \%^{\mathrm{a}}$ & $42.3 \%^{\mathrm{b}}$ & $39.1 \%^{\mathrm{a}}$ & $P<0.001$ \\
\hline & 17 years & $21.2 \%^{\mathrm{a}}$ & $37.6 \% \%^{\mathrm{a}}$ & $41.3 \%^{\mathrm{b}}$ & $P=0.002$ \\
\hline & 18 years & $0.0 \%{ }^{\mathrm{a}}$ & $41.7 \%^{\mathrm{a}}$ & $58.3 \%^{\mathrm{a}}$ & $P=0.400$ \\
\hline \multirow[t]{3}{*}{ BMI } & Normal weight & $13.1 \%^{\mathrm{a}}$ & $40.4 \%^{\mathrm{a}}$ & $46.5 \%^{\mathrm{b}}$ & $\mathrm{P}<0.001$ \\
\hline & Overweight & $33.3 \% \mathrm{a}$ & $47.4 \%^{\mathrm{b}}$ & $19 \%^{\mathrm{a}}$ & $P=0.034$ \\
\hline & Obese & $54.8 \%{ }^{\mathrm{a}}$ & $40.5 \%{ }^{\mathrm{b}}$ & $4.8 \%^{b}$ & $\mathrm{P}<0.001$ \\
\hline \multirow[t]{2}{*}{ Smoking } & Yes & $17.5 \%^{\mathrm{a}}$ & $43.9 \%^{\mathrm{b}}$ & $38.6 \%{ }^{\mathrm{a}}$ & $P=0.036$ \\
\hline & No & $18.8 \%^{\mathrm{a}}$ & $40.0 \%^{a}$ & $41.2 \%^{\mathrm{b}}$ & $\mathrm{P}<0.001$ \\
\hline \multirow[t]{2}{*}{ Physical exercise } & Yes & $19.8 \%^{\mathrm{a}}$ & $42.2 \%^{\mathrm{b}}$ & $38.1 \%^{\mathrm{a}}$ & $\mathrm{P}<0.001$ \\
\hline & No & $17.4 \%{ }^{\mathrm{a}}$ & $38.4 \%{ }^{\mathrm{a}}$ & $44.3 \%^{b}$ & $\mathrm{P}<0.001$ \\
\hline \multirow{2}{*}{$\begin{array}{l}\text { Family history of hyperten- } \\
\text { sion }\end{array}$} & Yes & $230 \%$ a & $212 \% \mathrm{~b}$ & $54 \% \mathrm{~b}$ & $P<0001$ \\
\hline & No & $10.8 \%^{\mathrm{a}}$ & $9.5 \%^{\mathrm{a}}$ & $30.1 \%^{\mathrm{b}}$ & $\mathrm{P}<0.001$ \\
\hline
\end{tabular}

Items in each row within a demographic category (i.e., Gender, Age) that share a letter are not significantly different

Table 3: Distribution of Study Participants by Demographic Variables

\begin{tabular}{lllll}
\hline Variables & & Hypertension (\%) & Pre hypertension (\%) & Normotensive (\%) \\
\hline Gender & Boys & $23.8 \%^{1}$ & $36.8 \%^{1}$ & $39.4 \%^{1}$ \\
& Girls & $11.9 \%^{2}$ & $45.2 \%^{1}$ & $42.9 \%^{1}$ \\
& & $\mathrm{P}<0.001$ & $\mathrm{P}=0.66$ & $\mathrm{P}=0.20$ \\
Age & & & & $39.1 \%^{1}$ \\
& 16 years & $18.6 \%^{1}$ & $42.3 \%^{1}$ & $41.3 \%^{2}$ \\
& 17 years & $21.2 \%^{1}$ & $37.6 \%^{2}$ & $58.3 \%^{3}$ \\
& 18 years & $0.0 \%^{1}$ & $41.7 \%^{3}$ & $\mathrm{P}<0.001$ \\
BMI & & $\mathrm{P}=0.29$ & $\mathrm{P}<0.001$ & $46.5 \%^{1}$ \\
& & $13.1 \%^{1}$ & $40.4 \%^{1}$ & $19.0 \%^{2}$
\end{tabular}




\begin{tabular}{|c|c|c|c|c|}
\hline & Obese & $\begin{array}{l}54.8 \%^{2} \\
P<0.001\end{array}$ & $\begin{array}{l}40.5 \%^{1} \\
P<0.001\end{array}$ & $\begin{array}{l}4.8 \%^{2} \\
P<0.001\end{array}$ \\
\hline Smoking & $\begin{array}{l}\text { Yes } \\
\text { No }\end{array}$ & $\begin{array}{l}17.5 \%^{1} \\
18.8 \%^{2} \\
P<0.001\end{array}$ & $\begin{array}{l}43.9 \%^{1} \\
40.0 \%^{2} \\
P<0.001\end{array}$ & $\begin{array}{l}38.6 \%^{1} \\
41.2 \%^{2} \\
P<0.001\end{array}$ \\
\hline Physical exercise & $\begin{array}{l}\text { Yes } \\
\text { No }\end{array}$ & $\begin{array}{l}19.8 \%^{1} \\
17.4 \%^{1} \\
P=0.14\end{array}$ & $\begin{array}{l}42.2 \%^{1} \\
38.4 \%^{2} \\
\mathrm{P}=0.046\end{array}$ & $\begin{array}{l}38.1 \%^{1} \\
44.3 \%^{1} \\
P=0.77\end{array}$ \\
\hline Family history of hypertension & $\begin{array}{l}\text { Yes } \\
\text { No }\end{array}$ & $\begin{array}{l}23.0 \%^{1} \\
10.8 \%^{2} \\
P<0.001\end{array}$ & $\begin{array}{l}21.2 \%^{1} \\
9.5 \%^{2} \\
P<0.001\end{array}$ & $\begin{array}{l}5.4 \%^{1} \\
30.1 \%^{2} \\
\mathrm{P}<0.001\end{array}$ \\
\hline
\end{tabular}

Items in each column within blood pressure category (i.e., Hypertension, Pre hypertension, Normotensive) that share a number are not significantly different.

\section{Discussion}

The prevalence rates of hypertension and pre-hypertension among adolescents in the current study were greater than adolescents in previous studies conducted in Nigeria and India (Ujunwa et al., 2013; Shetty et al., 2013). The prevalence rates were lower than adolescents living in Portugal (Silva et al., 2012) and almost the same as those of adolescents in India (Sundar et al., 2013). The inconsistency in the prevalence rates across studies may be attributed to criteria used to identify hypertension and prehypertension as well as population differences (Batiha et al., 2015; Sung et al., 1994) secondary to changes in socioeconomic circumstances of the communities and life styles (ALBashtawy, 2015a; ALBashtawy, Batiha, Tawalbeh, Tubaishat \& AlAzzam, 2015 Urbina et al., 2011). Researchers need to adhere to WHO standards in determining the pre- and hypertension criteria in order to cultivate global researchers' efforts to encounter these increasing phenomena.

\subsection{Demographic factors associated with hypertension and pre- hypertension}

Although most boys in the study were normotensive, the prevalence of hypertension was higher among boys, and comparable to a study conducted in Portugal (Silva et al., 2012). The reason for girls having low blood pressure compared to boys may be attributed to estrogen and its protective effect on the cardiovascular system, because estrogen causes vasodilatation by modulating the function of vascular endothelial cells (Mendelsohn \& Karas, 1999; Alhalaiqa et al. 2015). However, this explanation does not explain our finding that among girls, significantly more were prehypertensive than hypertensive or normotensive.

In the current study age was not associated with hypertension. Similar findings have been documented by Oyewole and Oritogun (2012) but disagree with a Nigerian study that found age was associated with increases in blood pressure among adolescents, as well the mid adolescent age group (13 - 15 years) (Ujunwa et al., 2013). When examining age across blood pressure levels, age was associated with pre-hypertension with 16-year-old students having a greater prevalence of pre-hypertension and 17 year olds having a greater prevalence of normotensive. Variation in study findings may be attributed to the adolescent age groups being examined. Future studies need to consider younger age groups when examining the association of age with hypertension and pre hypertension. A significant association of hypertension and pre hypertension with BMI was found in the current study. The prevalence of hypertension increased with increasing BMI and prevalence of prehypertension was significantly higher among overweight adolescents. These findings were comparable to studies of adolescents in other countries (Bahl et al., 2015; Rafraf et al., 2010). The prevalence of hypertensive and pre-hypertensive was greater among adolescents who were obese or overweight compared with the prevalence of normotensive. Conversely, the prevalence of normo- tensive was greater among adolescent who were normal weight. A study in Portugal found similar results (Silva et al., 2012) as did several studies which found a connection between BMI and hypertension (Abdul Razzak et al., 2013). When examining BMI across blood pressure levels, the data confirmed the impact of BMI on blood pressure: normotensive prevalence was associated with students of normal weight; pre-hypertensive prevalence was associated with overweight students, and hypertensive prevalence was associated with obesity. The current study finding indicates a major community health problem and a need to apply interventions that aim to prevent obesity and reduce weight such as dietary modification and encouraging physical exercise.

In the current study the prevalence of hypertension and normotensive was greater among nonsmoking students whereas the prevalence of pre-hypertension was greater among students who smoked, contrary to previous studies that found no significant association between smoking and blood pressure values (Amma et al., 2015; and Silva et al., 2012). Such contradictions may be attributed to the low percentage of smoking students $(11.7 \%)$ in the current study. Although the number of smokers was less compared with previous studies, efforts are still needed to reduce or eliminate these numbers. A campaign that shows the negative health outcomes of smoking, targeted at students, needs to be done.

Based on our findings, level of physical exercise was not statistically associated with hypertension. This result agrees with a study of high school adolescents in India (Sundar et al. 2013) and Portugal (Silva et al., 2012). When examining level of physical exercise across blood pressure levels, however, an unusual pattern was found. The prevalence of pre-hypertension was greater among those who exercised, and greater than the prevalence of hypertensive and normotensive levels. Future studies are needed to examine the impact of physical exercise among adolescents and need to include other factors such as diet, anxiety, depression and income that may be associated with hypertension and pre hypertension among adolescents (ALBashtawy, 2015 b; Khamaiseh \& ALBashtawy, 2015; Mu'taz, et al. 2016).

A family history of hypertension significantly increased the prevalence of both hypertension and pre-hypertension. Such a history may also have contributed to awareness and knowledge of hypertension, which are significant factors in early detection, diagnosis and controlling of blood pressure. Awareness of hypertension was positive, as about $61.0 \%$ of the 487 adolescents in the current study had some awareness regarding hypertension, compared to India, where only about $28.2 \%$ of the students had some awareness of hypertension (Sundar et al., 2013). Regardless of students' current awareness levels, more needs to be done to reduce the prevalence rate of hypertension and pre-hypertension and their complications.

\subsection{Implications to school nursing}

School health nurses, in collaboration with school administrators, need to emphasize primary prevention through the spread of knowledge about the importance of adopting a healthy life style and not smoking to decrease the chances of occurrence of hyper- 
tension. They need also to conduct regular screening programs to identify hypertension and pre hypertension to identify symptomatic students and assess those who are at risk as an initial step to prevent the occurrence of hypertension. Furthermore, nurses need to work with those who have already developed hypertension by focusing on secondary prevention activities that include early detection, and controlling and treating hypertension.

Awareness education to the families and the students also needs to address the downstream effects of early hypertension such as future cardiovascular disease, the cost of medications, hospitalization, work days lost, and disability (Pradeepa Prabhakaran, \& Mohan, 2012; Batiha \& AL Bashtawy, 2013).

\subsection{Limitations}

This study was limited to the data collected using self-reported questionnaires which make it difficult to confirm the students' responses. In addition, the study participants were selected from secondary governmental schools in Nablus city and therefore may not represent all adolescents throughout Palestine.

\subsection{Conclusion}

In conclusion, this study needs to be replicated and all Palestinian adolescents need to be included in the new study to generalize and confirm our findings. Several factors identified in this study were related to the prevalence of hypertension and pre hypertension. Regular screening for hypertension needs to be included into the school health nursing programs. There is a need to educate and increase awareness of students on the subject of hypertension so that they can understand the necessity of adopting healthy habits and a healthy life style.

\section{Conflict of interests}

The author(s) declared no potential conflicts of interest with respect to the research, authorship, and/or publication of this article.

\section{References}

[1] Abdul Razzak, R., Elmteri, A., Elkanderi, T., Ishaq, F., Eljasem, M., AlDuraie, S., \& Eldabos, L. (2013). Preliminary blood pressure screening in a representative sample of extremely obese Kuwaiti adolescents. Journal of obesity, 2013. http://dx.doi.org/10.1155/2013/968754.

[2] ALBashtawy, M. (2015a). Exploring the reasons why school students eat or skip breakfast. Nursing children and young people, 27(6), 16-22. http://dx.doi.org/10.7748/ncyp.27.6.16.e622.

[3] ALBashtawy, M. (2015b). Overweight and obesity interventions and prevention strategies. Nursing children and young people, 27(7), 16-21. http://dx.doi.org/10.7748/ncyp.27.7.16.e638.

[4] ALBashtawy, M., Alshloul, M., Alkawaldeh, A., Freij, M., ALRawajfah, O., Gharaibeh, H., \& Batiha, A. M. (2014). Looking at school nurses' roles in tackling overweight and obesity. British $\begin{array}{llll}\text { Journal of School Nursing, 9(8), 17-19. } & \text {. }\end{array}$ http://dx.doi.org/10.12968/bjsn.2014.9.8.402.

[5] ALBashtawy, M., Batiha, A., Tawalbeh, L., Tubaishat, A. \& AlAzzam, M. (2015). Self - medication among school students. Journal of School Nursing, 31(2), 110-116. http://dx.doi.org/10.1177/1059840514554837.

[6] Al-ghzawi, H., ALBashtawy, M., Azzeghaiby, S., \& Azzeghaiby, I. (2014). Alcohol use among adolescents. International Journal of Humanities and Social Science, 4(10), 167-175.

[7] Alhalaiqa F, Masa'Deh R, Batiha AM, and Deane K. (2014). Validity of Arabic Version of Beliefs about Medication Questionnaire. Clinical Nursing Research http://dx.doi.org/10.1177/1054773814545383.

[8] Alhalaiqa, F., Abu-shbeeb, I., Batiha, A. M., Masa'Deh, R., \& Amarneh, B. (2015). The Relation of Demographic Characteristics with Fatigue Levels among Coronary Heart Disease Patients: A Jordanian Study. Advanced Studies in Biology, 7(7), 301-322. http://dx.doi.org/10.12988/asb.2015.5418.
[9] Alkhawaldeh, A., ALOmari, O., ALBashtawy, M., Aljezawi, M. E., Suliman, M., Holm, M., \& Saifan, A. (2016). Long-term conditions in older adults using primary care services. Primary Health Care, 26(2), 31-35. http://dx.doi.org/10.7748/phc.26.2.31.s23.

[10] Amma, G. M., Vasudevan, B., \& Akshayakumar, S. (2015). Prevalence and determinants of prehypertension and hypertension among adolescents: a school based study in a rural area of Kerala, India. International Journal of Research in Medical Sciences, 3(1), 58-64. http://dx.doi.org/10.5455/2320-6012.ijrms20150111.

[11] Arima, H., Murakami, Y., Lam, T. H., Kim, H. C., Ueshima, H., Woo, J., \& Woodward, M. (2012). Effects of prehypertension and hypertension subtype on cardiovascular disease in the Asia-Pacific Region. Hypertension, 59(6), 1118-1123 http://dx.doi.org/10.1161/HYPERTENSIONAHA.111.187252.

[12] Bahl, D., Singh, K., and Sabharwal, M. (2015). Screening and Identifying Delhi school going adolescents (12-15 yrs) with Pre Hypertension and hypertension. International Journal of Scientific and Research Publications, 5(10), 1-7.

[13] Bashayreh, I., Saifan, A., Batiha, A. M., Timmons, S., \& Nairn, S. (2015). Health professionals' perceptions regarding family witnessed resuscitation in adult critical care settings. Journal of clinical nursing, 24(17-18), 2611-2619. http://dx.doi.org/10.1111/jocn.12875.

[14] Batiha AM \& AL Bashtawy M. (2013). Knowledge of Philadelphia University students regarding blood Donation. Transfusion Medicine; 23,195- 198. http://dx.doi.org/10.1111/tme.12027.

[15] Batiha, A. M., AlAzzam, M., ALBashtawy, M., Tawalbeh, L., Tubaishat, A., \& Alhalaiqa, F. N. (2015). The relationship between hypertension and anthropometric indices in a Jordanian population. Advanced Studies in Biology, 7(5), 233-243. http://dx.doi.org/10.12988/asb.2015.5214.

[16] Batiha, A. M., Alhalaiqa, F. N., Bashayreh, I., Saifan, A., Al-Zaru, I. M., \& Omran, S. (2015). Comprehensive Oral Care Program for Intubated Intensive Care Unit Patients. Advanced Studies in Biology, 7(6), 259-273. http://dx.doi.org/10.12988/asb.2015.5213.

[17] Batiha, A.M., Obead, K.A., Alhalaiqa, F.N., Kawafha, M.M., ElRazek, A.A., Albashtawy, M., Saifan, A., Ruz, M.E.A. and Al Ewaidat, H. (2015). Quality of Life and Fatigue among Jordanian Cancer Patients. Iranian Journal of Public Health, 44(12), 1704.

[18] Chobanian AV, Bakris GL, Black HR, et al. (2003b). The Seventh Report of the Joint National Committee on prevention, detection, evaluation, and treatment of high blood pressure: the JNC 7 report. JAMA. 2003; 289:2560-72. http://dx.doi.org/10.1001/jama.289.19.2560.

[19] Chobanian, A. V., Bakris, G. L., Black, H. R., et al. (2003a). "Seventh report of the joint national committee on prevention, detection, evaluation, and treatment of high blood pressure," Hypertension, 42(6), pp. 1206-1252, 2003. http://dx.doi.org/10.1161/01.HYP.0000107251.49515.c2.

[20] Ferdinand, K. C., \& Pacini, R. S. (2007). New evidence confirms risks associated with prehypertension and benefits of therapeutic lifestyle changes in management. Journal of the Cardiometabolic Syndrome, 2(4), 302-304. http://dx.doi.org/10.1111/j.15594564.2007.07620.x.

[21] Khamaiseh, A. \& ALBashtawy, M. (2013). Oral health knowledge, attitudes, and practices among secondary school students. British Journal of School Nursing, 8 (4), 194-2001. http://dx.doi.org/10.12968/bjsn.2013.8.4.194.

[22] Khamaiseh, A., \& ALBashtawy, M. (2015). Prevalence of obesity and physical inactivity behaviors among nursing students in Mutah University, Jordan. World Journal of Medical Sciences, 12(2), 95102.

[23] Lucini, D., Mela, G. S., Malliani, A., \& Pagani, M. (2002). Impairment in cardiac autonomic regulation preceding arterial hypertension in humans insights from spectral analysis of beat-by-beat cardiovascular variability. Circulation, 106(21), 2673-2679. http://dx.doi.org/10.1161/01.CIR.0000039106.89299.AB.

[24] Mendelsohn, M. E., \& Karas, R. H. (1999). The protective effect of estrogen on the cardiovascular system. The New England Journal of Medicine, 340(23), 180-91.

[25] Mu'taz, M. D., Alrimawi, I., Saifan, A. R., \& Batiha, A. M. (2016). Hand Hygiene Knowledge, Practices and Attitudes among Nurses and Physicians. Health, 8(05), 456. http://dx.doi.org/10.4236/health.2016.85048.

[26] National High Blood Pressure Education Program Working Group on High Blood Pressure in Children and Adolescents. (2004). the fourth report on the diagnosis, evaluation, and treatment of high blood pressure in children and adolescents. Pediatrics, 2114(2). 
[27] Oyewole, O. O., \& Oritogun, K. S. (2013). Pre-Hypertension and Hypertension in Adolescence: How much does it occur in a Nigerian Community? West African Journal of Medicine, 31(2), 71-75.

[28] Park, K. (2007). Park's textbook of preventive and social medicine. $19^{\text {th }}$ ed. Banarsidas Bhanot Publisher India: Bhanot

[29] Pradeepa, R., Prabhakaran, D., \& Mohan, V. (2012). Emerging economies and diabetes and cardiovascular disease. Diabetes Tech$\begin{array}{llll}\text { nology } \quad \text { \& } \quad \text { Therapeutics, } & \text { 14(S1), }\end{array}$ http://dx.doi.org/10.1089/dia.2012.0065.

[30] Rafraf, M., Gargari, B. P., \& Safaiyan, A. (2010). Prevalence of prehypertension and hypertension among adolescent high school girls in Tabriz, Iran. Food and Nutrition Bulletin, 31(3), 461-465. http://dx.doi.org/10.1177/156482651003100308.

[31] Shetty, S., Shetty, S. S., Sasidharan, S., \& Shenoy, V. (2013). Prevalence of pre-hypertension and hypertension in asymptomatic urban school going children of Mangalore and its correlation with BMI. Journal of Dental and Medical Sciences, 9(1), 76-79 http://dx.doi.org/10.9790/0853-0917679.

[32] Silva, D., Matos, A., Magalhães, T., Martins, V., Ricardo, L., \& Almeida, H. (2012). Prevalência de hipertensão arterial em adolescentes portugueses da cidade de Lisboa. Revista Portuguesa de $\begin{array}{lll}\text { Cardiologia, } & \text { 31(12), 789-794. }\end{array}$ http://dx.doi.org/10.1016/j.repc.2012.02.022.

[33] Sundar, J. S, Parameswari, S., Valarmarthi, S., Kalpana, S., \& Shantharam, D. (2013). Prevalence and Determinants of Hypertension among Urban School Children in the Age Group of 13-17 Years in, Chennai, Tamilnadu. Epidemiology, 3(3). http://dx.doi.org/10.4172/2161-1165.1000130.

[34] Sung, R. Y. T., Lam, Y. M., \& Leung, S. S. F. (1994). Blood pressure in Hong Kong Chinese children: correlation with anthropometric data. Journal of Hong Kong College of Cardiology, 2, 99-106.

[35] Tawalbeh, L., Tubaishat, A. , Batiha, A. , AlAzzam, M. \& ALBashtawy, M. (2015).The Relationship between Social Support and Adherence to Healthy Lifestyle among Patients with Coronary Artery Disease in the North of Jordan. Clinical Nursing Research, 24(2):121-38, http://dx.doi.org/10.1177/1054773813501194.

[36] Ujunwa, F. A., Ikefuna, A. N., Nwokocha, A. R., \& Chinawa, J. M. (2013). Hypertension and prehypertension among adolescents in secondary schools in Enugu, South East Nigeria. Italian Journal of Pediatrics, 39(70), 1824-7288. http://dx.doi.org/10.1186/1824 7288-39-70.

[37] Urbina, E. M., Khoury, P. R., McCoy, C., Daniels, S. R., Kimball T. R., \& Dolan, L. M. (2011). Cardiac and vascular consequences of pre-hypertension in youth. The Journal of Clinical Hypertension, 13(5), 332-342. $\quad$ http://dx.doi.org/10.1111/j.17517176.2011.00471.x

[38] Wang, Y., \& Wang, Q. J. (2004). The prevalence of prehypertension and hypertension among US adults according to the new joint national committee guidelines: new challenges of the old problem. Archives of Internal Medicine, 164(19), 2126-2134. http://dx.doi.org/10.1001/archinte.164.19.2126.

[39] World Health Organization (1997). World Health Organization Report of a WHO Consultation on Obesity. Obesity Preventing and Managing the Global Epidemic Geneva, Switzerland, Author.

[40] World Health Organization (2008) Causes of Death. [Online database].

Geneva, (http://www.who.int/healthinfo/global_burden_disease/cod_2008_s ources_methods.pdf.). 